Pesq. Vet. Bras. 37(5):459-464, maio 2017 DOI: $10.1590 / \mathrm{S} 0100-736 \mathrm{X} 2017000500006$

\title{
Isolamento e caracterização de espécies de Pythium de ambientes aquáticos no Estado do Rio Grande do Sul e avaliação da patogenicidade em modelo experimental ${ }^{1}$
}

\author{
Cristina G. Zambrano², Anelise O.S. Fonseca² , Júlia S.S. Valente ${ }^{2}$, Caroline Q. Braga ${ }^{2}$, \\ Elisa S.V. Sallis ${ }^{3}$, Maria Isabel Azevedo ${ }^{4}$, Carla Weiblen ${ }^{4}$, Janio M. Santurio ${ }^{4}$, Sonia \\ A. Botton ${ }^{4}$ e Daniela Isabel B. Pereira ${ }^{2 *}$
}

\begin{abstract}
Zambrano C.G., Fonseca A.O.S., Valente J.S.S., Braga C.Q., Sallis E.S.V., Azevedo M.I., Weiblen C., Santurio J.M., Botton S.A. \& Pereira D.I.B. 2017. [Isolation and characterization of Pythium species from swampy areas in the Rio Grande do Sul, Brazil, and evaluation of pathogenicity in an experimental model.] Isolamento e caracterização de espécies de Pythium de ambientes aquáticos no Estado do Rio Grande do Sul e avaliação da patogenicidade em modelo experimental. Pesquisa Veterinária Brasileira 37(5):459-464. Laboratório de Micologia, Instituto de Biologia, Departamento de Microbiologia e Parasitologia, Universidade Federal de Pelotas, Campus Universitário s/n, Pelotas, RS 96160-000, Brazil. E-mail: danielabrayer@gmail.com

One hundred and eighty-six water samples from swampy areas were collected in 13 municipalities of South, Central and West regions of Rio Grande do Sul, Brazil, in order to isolate and characterize Pythium species and assess their pathogenicity using rabbits as experimental model. Different Pythium species were isolated from $22(11.8 \%)$ water samples, including P. insidiosum ( $\mathrm{n}=1)$, P. catenulatum $(\mathrm{n}=3)$, P. pachycaule voucher $(\mathrm{n}=1)$, P. rhizo-oryzae $(\mathrm{n}=3)$, P. torulosum $(\mathrm{n}=4)$ e Pythium spp. $(\mathrm{n}=10)$. Zoospores of these microorganisms were produced in vitro and inoculated subcutaneously into rabbits, which were assessed over 45 days. Only $P$. insidiosum showed pathogenicity, causing pythiosis in the experimental model.
\end{abstract}

INDEX TERMS: Pythium insidiosum, oomycete, pythiosis, freshwater ecosystems, rabbits.

RESUMO.- Foram coletadas 186 amostras de água de ambientes pantanosos em 13 municípios das regiões Sul, Central e Oeste do Rio Grande do Sul, Brasil, com o objetivo de isolar e caracterizar espécies de Pythium e avaliar a sua patogenicidade empregando coelhos como modelo experimental. Em 11,8\% (n=22) das águas coletadas foram isoladas diferentes espécies de Pythium incluindo: P. insi-

\footnotetext{
${ }^{1}$ Recebido em de agosto de 2016.

Aceito para publicação em 18 de outubro de 2016.

${ }^{2}$ Laboratório de Micologia, Instituto de Biologia, Departamento de Microbiologia e Parasitologia, Universidade Federal de Pelotas (UFPel), Campus Capão do Leão, Prédio 18, Pelotas, RS 96010-610, Brasil. *Autor para correspondência: danielabrayer@gmail.com

${ }^{3}$ Laboratório Regional de Diagnóstico, Departamento de Patologia, Faculdade de Veterinária, UFPel, Campus Capão do Leão, Prédio 18, Pelotas, RS 96010-610, Brasil.

${ }^{4}$ Laboratório de Pesquisas Micológicas, Universidade Federal de Santa Maria (UFSM), Av. Roraima 1000, Camobi, Santa Maria, RS 97105-900, Brasil.
}

diosum $(\mathrm{n}=1)$, P. catenulatum $(\mathrm{n}=3)$, P. pachycaule voucher $(\mathrm{n}=1), P$. rhizo-oryzae $(\mathrm{n}=3), P$. torulosum $(\mathrm{n}=4)$ e Pythium spp. $(\mathrm{n}=10)$. Zoósporos desses micro-organismos foram produzidos in vitro e inoculados por via subcutânea em coelhos, os quais foram avaliados durante 45 dias. Dentre os oomicetos testados, apenas $P$. insidiosum evidenciou patogenicidade, causando pitiose no modelo experimental, evidenciando que, em nossas condições, apenas esta espécie de Pythium é patógena para mamíferos.

TERMOS DE INDEXAÇÃO: Pythium insidiosum, oomicetos, pitiose, ecossistemas de água doce, coelhos.

\section{INTRODUÇÃO}

Oomicetos do gênero Pythium compreendem mais de 140 espécies reconhecidas, sendo 41 destas descritas a partir do ano 2000 (Kageyama 2014). As espécies de Pythium são geneticamente diferentes e exibem variações em termos de virulência, hospedeiro e distribuição, habitando 
ecossistemas de água doce, salgada e ambientes terrestres (Jiang\&Tyler 2012, Adhikari et al. 2013, Kageyama 2014). A maior parte das espécies são sapróbias ou patógenos de plantas, algas, peixes, insetos e mamíferos (Kageyama 2014).

Como típico oomiceto aquático, o gênero Pythium realiza parte de seu ciclo biológico em águas de rios, lagoas e lagos. Dentro deste habitat são mais comumente encontrados nas águas rasas próximas às margens (Alexopoulos et al. 1996). 0 ciclo biológico aquático para $P$. insidiosum está bem caracterizado. Segundo Miller (1983) e Mendoza et al. (1993) o acúmulo de água estagnada em lagos, açudes e pântanos favorece a reprodução assexuada do micro-organismo, que coloniza plantas aquáticas para o seu desenvolvimento e reprodução. Durante o ciclo há a formação de zoósporos infectantes, que são liberados nas águas e movimentam-se até encontrar outra planta onde completam e reiniciam seu ciclo. Todavia, em P. insidiosum, patógeno para mamíferos, esses zoósporos ao serem liberados nas águas podem ser atraídos para o pelo dos hospedeiros, penetram na pele através de lesões pré-existentes e iniciam o processo de infecção, caracterizando a doença (Mendoza et al. 1996).

Pitiose é frequente em mamíferos, notadamente equinos, homem e caninos que habitam regiões de clima tropical, subtropical e temperado. Embora a enfermidade tenha sido descrita em vários países (Mendoza et al. 1996, Gaastra et al. 2010), o maior número de casos de pitiose humana é relatado na Tailândia (Krajaejun et al. 2006) e a doença em equinos é endêmica no Brasil, particularmente no Pantanal Brasileiro (Mendoza et al. 1996, Santos et al. 2014) e na região Sul do Brasil, no estado do Rio Grande do Sul (Marcolongo-Pereira et al. 2012, Weiblen et al. 2015).

Durante muitos anos $P$. insidiosum foi a única espécie reconhecida como patógeno para mamíferos (De Cock et al. 1987, Alexopoulos et al. 1996, Mendoza et al. 1996, Gaastra et al. 2010). Entretanto, o relato de dois casos de infecção por Pythium aphanidermatum, um patógeno típico de plantas, no homem aponta que outras espécies do gênero podem ter potencial patogênico para mamíferos (Calvano et al. 2011, Farmer et al. 2015).

Considerando que o gênero Pythium compreende várias espécies que compartilham o mesmo nicho ecológico e como há o relato de outra espécie patógena para mamíferos, além de P. insidiosum, torna-se relevante avaliar se outras espécies de Pythium que coabitam o mesmo ecossistema de água doce podem ser patógenas para os animais.

Este trabalho teve como objetivos isolar e caracterizar espécies de Pythium que habitam ambientes pantanosos no Rio Grande do Sul, Brasil e avaliar a patogenicidade das espécies isoladas empregando coelhos como modelo experimental.

\section{MATERIAL E MÉTODOS}

Coleta das amostras de água e isolamento de espécies de Pythium. As amostras de água foram coletadas em 13 diferentes municípios do Rio Grande do Sul, Brasil, durante os anos de 2013 a 2015 (Fig.1), conforme metodologia previamente descrita por Supabandhu et al. (2008). As coletas ocorreram em diferentes es-

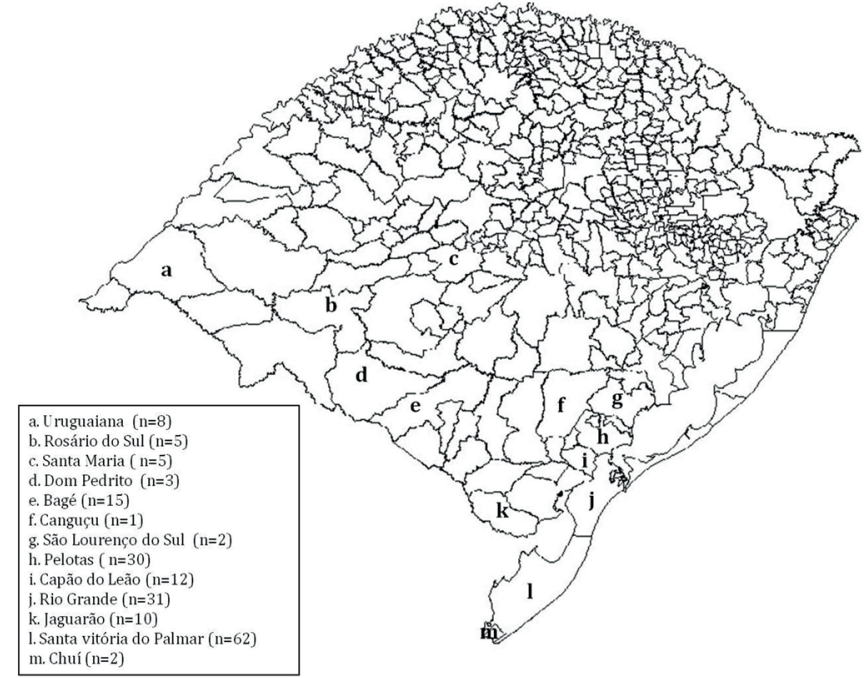

Fig.1. Municípios onde foram realizadas as coletas de água no Rio Grande do Sul, Brasil, no período de 2013 a 2015.

tações do ano e priorizou-se a coleta de água em lagos e açudes de locais com histórico de pitiose em animais. As amostras de água foram acondicionadas em frascos estéreis e a amostragem foi realizada a 5 ou $10 \mathrm{~cm}$ da superfície, nas margens com vegetação, sendo coletados 3 ou 4 pontos opostos, dependendo da extensão da área.

Em cada frasco adicionou-se 10 a 20 iscas de cabelo humano, de aproximadamente $3 \mathrm{~cm}$, previamente esterilizadas. Os frascos foram incubados em estufa bacteriológica a $37^{\circ} \mathrm{C}$ durante 48 horas. Após esse período, a água era drenada e as iscas assepticamente coletadas e transferidas para placas de Petri contendo o meio de cultura agar VP3 (Ali-Shtayeh et al. 1986). As placas foram incubadas a $37^{\circ} \mathrm{C}$ por $48-72$ horas, sendo examinadas diariamente. Colônias transparentes ou esbranquiçadas, submersas com curto micélio aéreo e padrão delicadamente radiado foram consideradas suspeitas de Pythium. Pequenos fragmentos dessas colônias foram submetidos a exame direto entre lâmina e lamínula, corado com azul de algodão, para observação da morfologia das hifas. Quando hifas cenocíticas foram observadas, subcultivos para tubos contendo agar levedura $0,1 \%$ foram realizados e incubados a $37^{\circ} \mathrm{C}$ por $48-72$ horas. Posteriormente, os isolados foram submetidos à identificação morfológica e molecular.

Identificação morfológica e molecular. A identificação morfológica foi realizada através da técnica de zoosporogênese (Mendoza \& Prendas, 1988) para identificação de zoosporângios e zoósporos característicos de Pythium. Blocos de agar dos isolados positivos na zoosporogênese foram transferidos para frascos tipo Erlenmeyer contendo $150 \mathrm{~mL}$ de caldo Sabouraud, incubados a $37^{\circ} \mathrm{C}$ em agitação constante a $120 \mathrm{rpm}$ durante cinco dias. A extração total do DNA foi realizada de acordo com o protoloco descrito por Möller et al. (1992) e modificado por Klassen et al. (1996). A reação em cadeia de polimerase (PCR) das regiões ITS e cox II e o sequenciamento de DNA foram realizados conforme descrito por Azevedo et al. (2012). As sequências obtidas foram analisadas utilizando-se o pacote de programas Staden e comparadas a sequências de referência de Pythium disponíveis no GenBank (http:// www.ncbi.nlm.nih.gov).

Avaliação da patogenicidade de espécies de Pythium em modelo experimental. As espécies de Pythium obtidas a partir das amostras de água avaliadas no presente estudo foram experimentalmente inoculadas em coelhos. Cada isolado de Pythium foi inoculado em dois coelhos sadios, da raça Nova Zelândia, fê- 
meas, de três meses de idade, totalizando 18 coelhos. Os animais foram inoculados por via subcutânea no lado direito da região das costelas com $1 \mathrm{~mL}$ de meio de indução contendo aproximadamente 20.000 zoósporos viáveis do isolado de Pythium testado, preparados conforme descrito por Pereira et al. (2007). Os coelhos foram mantidos em gaiolas individuais sob condições adequadas de higiene, luz e temperatura, recebendo água ad libitum e ração de acordo com peso corporal. Os animais foram inspecionados diariamente, durante 45 dias, para avaliação do desenvolvimento das lesões. Adicionalmente, a evolução das lesões foi medida a cada cinco dias, no sentido horizontal e transversal $\left(\mathrm{cm}^{2}\right)$, com auxílio de paquímetro. Ao final do experimento, os coelhos foram submetidos à necropsia e fragmentos representativos das lesões subcutâneas foram coletados, fixados em formalina 10\%, rotineiramente processados para análise histopatológica e submetidos à coloração de hematoxilina-eosina e Grocott. 0 procedimento foi aprovado pelo Comitê de Ética em Experimentação Animal da Universidade Federal de Pelotas (protocolo no 3682).

\section{RESULTADOS}

Um total de 186 amostras de água foi coletado em 106 localidades dos municípios de: Bagé, Camaquã, Canguçu, Capão do Leão, Chuí, Dom Pedrito, Jaguarão, Pelotas, Rio Grande, Rosário do Sul, Santa Maria, Santa Vitória do Palmar e Uruguaiana. Entre as amostras coletadas, em 14,5\% (27/186) houve o isolamento de micro-organismos cujas características macro e micromorfológicas foram condizentes com o gênero Pythium e em 85,5\% (159/186) das amostras não houve isolamento de oomicetos. A estação do ano com o maior número de isolados foi o verão $(n=14)$, especialmente no mês de janeiro, seguido pelo outono $(n=13)$, principalmente no mês de abril.

Dos 27 isolados suspeitos na identificação morfológica,

Quadro 1. Isolados de Pythium obtidos de ambientes aquáticos no Rio Grande do Sul, Brasil, no período de 2013 a 2015

\begin{tabular}{|c|c|c|}
\hline Isolado & Origem do isolado & Identificação \\
\hline $\mathrm{P} 1$ & Capão do Leão & Pythium torulosum* \\
\hline P 2 & Capão do Leão & Pythium spp. \\
\hline P 3 & Capão do Leão & Pythium spp. \\
\hline P 4 & Capão do Leão & Pythium spp. \\
\hline P 5 & Chuí & Pythium catenulatum* \\
\hline P 6 & Chuí & Pythium torulosum* \\
\hline P 7 & Jaguarão & Pythium spp.* \\
\hline P 8 & Pelotas & Pythium spp.* \\
\hline P 9 & Rio Grande & Pythium spp. \\
\hline P 10 & Rio Grande & Pythium torulosum \\
\hline P 11 & Santa Vitória do Palmar & Pythium spp.* \\
\hline P 12 & Santa Vitória do Palmar & Pythium rhizo-oryzae* \\
\hline P 13 & Santa Vitória do Palmar & Pythium rhizo-oryzae \\
\hline P 14 & Santa Vitória do Palmar & Pythium rhizo-oryzae \\
\hline P 15 & Santa Vitória do Palmar & Pythium torulosum \\
\hline P 16 & Santa Vitória do Palmar & Pythium pachycaule voucher* \\
\hline P 17 & Santa Vitória do Palmar & Pythium spp. \\
\hline P 18 & Santa Vitória do Palmar & Pythium spp. \\
\hline P 19 & Santa Vitória do Palmar & Pythium catenulatum \\
\hline P 20 & Uruguaiana & Pythium spp. \\
\hline P 21 & Uruguaiana & Pythium catenulatum \\
\hline P 22 & Uruguaiana & Pythium insidiosum* \\
\hline
\end{tabular}

* Isolados experimentalmente inoculados em coelhos.

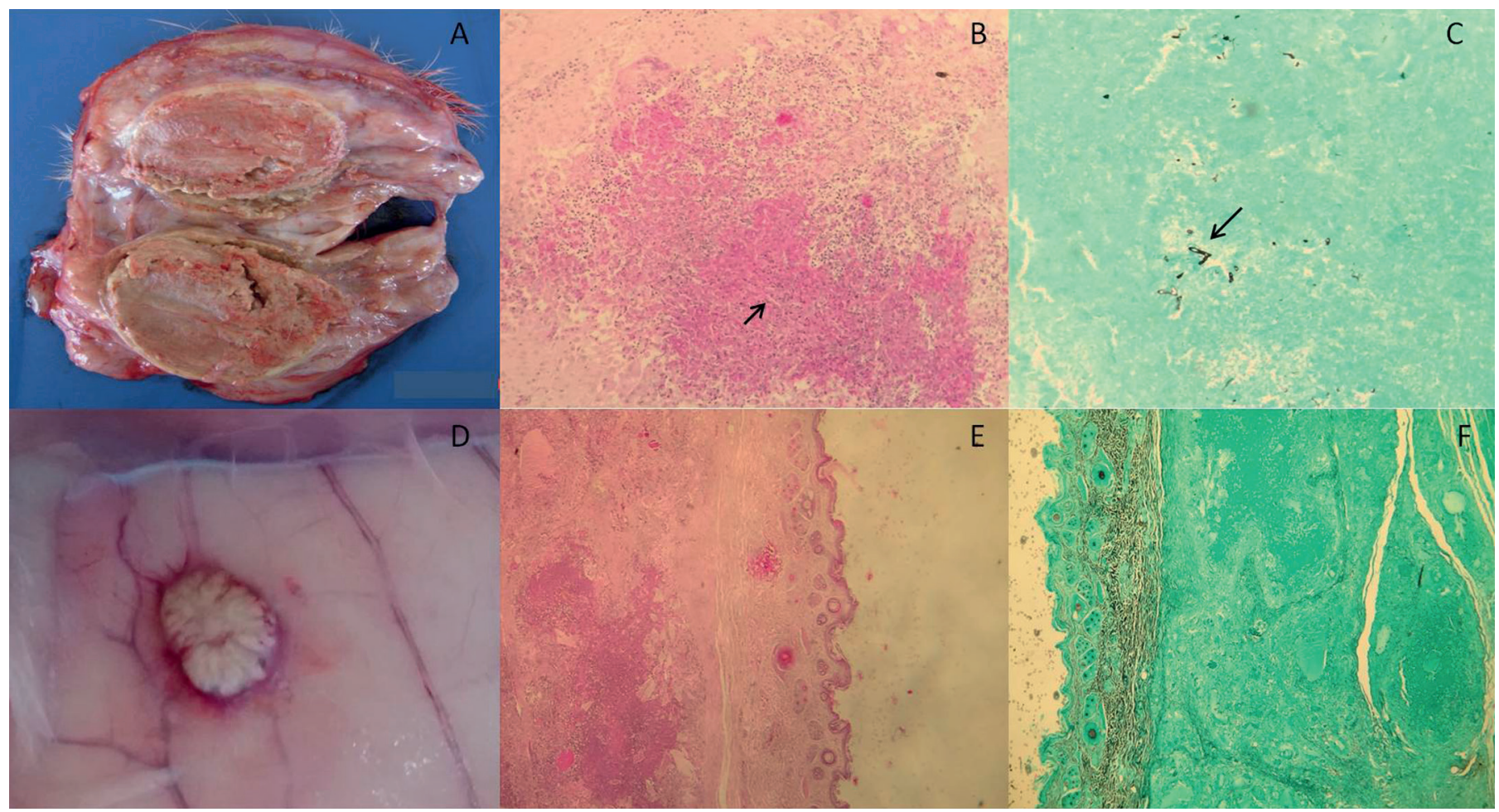

Fig.2. (A,B,C) Pele, pitiose experimental em coelho inoculado com Pythium insidiosum. (A) Superfície de corte do nódulo cutâneo revelando extensa área de necrose branco-rosada e vascularizada. (B) Área focal de necrose eosinofílica com imagens negativas tubuliformes de hifas de Pythium insidiosum (seta). HE, obj.10x. (C) Numerosas hifas, bem delimitadas e fortemente impregnadas pela prata (seta). Técnica de Grocott, obj.10x. (D,E,F) Pele, lesão experimental em coelhos inoculados com Pythium spp. (D) Nódulo subcutâneo contendo exsudato purulento em seu interior. (E) Extensa área de necrose cercada por quantidade variável de neutrófilos. HE, obj.10x. (F) Técnica de Grocott confirmando a ausência de hifas no interior da lesão. Obj.10x. 
em 22 a análise molecular confirmou gênero Pythium (Quadro 1). P. insidiosum foi obtido em apenas uma amostra de água oriunda do município de Uruguaiana. A origem e a identificação das espécies de Pythium estão demonstradas no Quadro 1.

A partir da identificação molecular das espécies, selecionaram-se os seguintes isolados de origem ambiental para a inoculação experimental em coelhos: $P$. insidiosum $(\mathrm{n}=1), P$. pachycaule voucher $(\mathrm{n}=1)$, . torulosum $(\mathrm{n}=2)$, Pythium spp. $(\mathrm{n}=3), P$. rhizo-oryzae $(\mathrm{n}=1)$ e $P$. catenulatum $(\mathrm{n}=1)$.

Observou-se que os dois coelhos que foram inoculados com $P$. insidiosum isolado do ambiente desenvolveram nódulos subcutâneos idênticos à pitiose experimental em coelhos quando inoculados com isolados de origem clínica. Os nódulos subcutâneos, após 20 dias de inoculação, apresentavam medidas de aproximadamente $20 \mathrm{~cm}^{2}$ de área e ao final do experimento mediam $30 \mathrm{~cm}^{2}$. A macroscopia dessas lesões revelou massas fibrosas subcutâneas e multilobuladas. Ao corte eram firmes, branco-rosadas e bastante vascularizadas (Fig.2A). Histologicamente evidenciou-se na derme e tecido subcutâneo áreas multifocais a coalescentes de necrose constituídas por infiltrados inflamatórios, predominantemente de eosinófilos. Nas áreas de necrose observaram-se imagens tubuliformes negativas, referentes às hifas de $P$. insidiosum que se apresentavam rodeadas por áreas irregulares e eosinofílicas, condizentes com reações de Splendori-Hoeppli, estando algumas destas reações, delimitadas por células gigantes tipo Langerhans (Fig.2B). Verificou-se também, intensa proliferação de tecido conjuntivo fibroso com presença de eosinófilos, plasmócitos, linfócitos e macrófagos. Na técnica metenamina nitrato de prata de Grocott foram visualizadas hifas com paredes espessas, marrons, esparsamente septadas e irregularmente ramificadas, localizadas preferencialmente na periferia das áreas de necrose (Fig.2C).

Os coelhos inoculados com os isolados ambientais, $P$. catenulatum, $P$. pachycaule voucher, P. rhizo-oryzae, $P$. torulosum e Pythium spp. desenvolveram nódulos subcutâneos pequenos (com tamanhos que variaram de $1 \mathrm{~cm}^{2}$ a $2 \mathrm{~cm}^{2}$ ) 20 dias após a inoculação subcutânea e mantiveram-se no mesmo tamanho até o momento da necropsia dos animais, 45 dias após a inoculação. As lesões estavam firmemente aderidas ao tecido subcutâneo e apresentavam-se como pequenos nódulos, contendo pus em seu interior (Fig.2D). Microscopicamente, as lesões cutâneas (derme profunda) e tecido subcutâneo foram similares, caracterizando-se por piogranulomas multifocais a coalescentes, com extensões variadas, constituídos por uma área central de necrose, cercadas por quantidade variável de neutrófilos e eosinófilos, íntegros ou degenerados que, por sua vez eram rodeados por macrófagos, células epitelioides, com ocasionais células gigantes. Infiltrado de linfócitos ocorria perifericamente associado ao tecido conjuntivo fibroso neoformado (Fig.2E). Na técnica de Grocott, não foram evidenciadas hifas fúngicas (Fig.2F).

\section{DISCUSSÃO E CONCLUSÃO}

Os oomicetos constituem um grupo de organismos eucariotos distribuídos em ecossistemas de água doce e am- bientes terrestres. Enquanto alguns gêneros de oomicetos são sapróbios, outros são patógenos, podendo causar graves infecções em mamíferos (Lagenidium e Pythium), plantas (Pythium e Phytophthora), insetos (Lagenidium e Pythium) e peixes (Achlya, Saprolegnia e Pythium) (Mendoza \& Vilella 2013). Em mamíferos, $P$. insidiosum é a espécie patógena de maior relevância, determinando a pitiose, uma doença de rápida evolução, difícil tratamento e prognóstico desfavorável aos hospedeiros suscetíveis (Gaastra et al. 2010). A enfermidade é mais frequente em equinos, caninos e homem que habitam áreas pantanosas em regiões de clima tropical, subtropical e temperado (Mendoza et al. 1996, Gaastra et al. 2010).

A correlação entre a enfermidade e a presença de água é uma observação frequente em todos os relatos da doença, sendo comum a ocorrência da pitiose após o acesso dos hospedeiros suscetíveis a lagos, lagoas e pântanos (Chaffin et al. 1995, Mendoza et al. 1996). Confirmando esta constatação, estudos prévios realizados na Austrália (Miller 1983), Tailândia (Supabandhu et al. 2008) e Estados Unidos (Presser \& Goss 2015) demonstraram a presença de $P$. insidiosum em nichos ecológicos aquáticos, incluindo áreas pantanosas, lagos, lagoas e água utilizada para irrigação de lavouras de arroz.

No presente estudo apenas um isolado de $P$. insidiosum foi obtido a partir das águas avaliadas. Este resultado difere de Supabandhu et al. (2008) que obtiveram 59 isolados de $P$. insidiosum a partir da análise de 325 amostras de água oriundas de lavouras de arroz, canais de irrigação e águas de reservatório na Tailândia e de Presser \& Goss (2015) que isolaram $P$. insidiosum em 11 das 19 amostras de água oriundas de lagos e lagoas nos Estados Unidos.

Embora o Rio Grande do Sul seja considerado endêmico para pitiose equina, o baixo número de isolados obtidos neste estudo pode ser justificado provavelmente pelos seguintes fatos: técnica de iscagem empregada para o isolamento; probabilidade de baixa quantidade de $P$. insidiosum nos ambientes aquáticos; ou meio de cultura empregado.

Supabandhu et al. (2008) afirmaram que a técnica de iscagem tem baixa sensibilidade e nos casos em que $P$. insidiosum está presente em quantidades baixas, esse método pode não ser uma ferramenta efetiva para detecção deste micro-organismo. Estes mesmos autores ponderaram em seu trabalho que a recuperação do micro-organismo pela técnica de iscagem por amostra de água foi baixa. Adicionalmente, estes autores sugerem que o oomiceto pode colonizar uma pequena área do nicho aquático formando agregados dentro de um habitat, ao invés de espalharem-se uniformemente através de toda a fonte de água, o que contribuiria para o insucesso dos isolamentos.

Por outro lado, o meio de cultura também pode influenciar o sucesso de isolamento de Pythium. Pittis \& Colquhoun (1984) afirmaram que o isolamento de Pythium spp. de habitat aquático por métodos laboratoriais é geralmente difícil, uma vez que o crescimento bacteriano acompanha o crescimento micelial. Similarmente, Plaats-Niterink (1975) ao utilizar diferentes meios seletivos também obtiveram resultados limitados. Entretanto, segundo Ali-Shtayeh et al. (1986), diferentes espécies de Pythium podem ser facil- 
mente isoladas do solo através do uso de meio VP3, o que está de acordo com os resultados obtidos nesta pesquisa. Diferentemente, Supabandhu et al. (2008) e Presser \& Goss (2015) empregaram agar Sabouraud dextrose acrescido de antimicrobianos.

No presente estudo isolaram-se outras espécies de Pythium, as quais foram selecionadas para testar a patogenicidade em animais, uma vez que foram hábeis para colonizar as iscas de cabelo e crescer a $37^{\circ} \mathrm{C}$. Este é o primeiro estudo a avaliar a patogenicidade de outras espécies de Pythium, que não P. insidiosum, em modelo experimental.

Neste estudo, os coelhos experimentais inoculados com zoósporos de $P$. insidiosum desenvolveram lesões clínicas e patológicas idênticas à pitiose experimental em coelhos induzida com isolados de $P$. insidiosum oriundos de equinos (Fig.2), conforme relatada previamente por Miller \& Campbell (1983), Santurio et al. (2003), Pereira et al. (2007, 2008) e Fonseca et al. (2015). A reprodução experimental da pitiose com um isolado de $P$. insidiosum de origem ambiental comprova a patogenicidade dessa espécie para mamíferos, bem como confirma que os ambientes pantanosos são a fonte de infecção e mantêm o ciclo biológico do oomiceto, que utiliza plantas aquáticas para o seu desenvolvimento e reprodução formando zoósporos infectantes, conforme previamente descrito por Chaffin et al. (1995), Miller (1983), Mendoza et al. (1993), Supabandhu et al. (2008) e Fonseca et al. (2014). Adicionalmente, a relação filogenética desse isolado foi previamente estudada por Azevedo et al. (2012), os quais demonstraram que isolados brasileiros de $P$. insidiosum oriundos de diferentes regiões do Brasil foram geneticamente similares, compartilhando o mesmo ancestral comum. Esses dados, juntamente com a capacidade de $P$. insidiosum ambiental de causar a pitiose em animais experimentais, evidenciam que a patogenicidade de $P$. insidiosum independe da origem do isolado.

Os isolados de $P$. catenulatum, $P$. pachycaule voucher, $P$. rhizo-orizae, $P$. tolurosum e Pythium spp. testados não demonstraram patogenicidade aos coelhos. As lesões histológicas observadas no local de inoculação foram características de uma reação inflamatória à presença de antígenos estranhos ao organismo do hospedeiro.

No presente estudo, dos oomicetos aquáticos isolados, apenas $P$. insidiosum foi capaz de causar a pitiose no modelo experimental, evidenciando que, em nossas condições, apenas esta espécie de Pythium é patógena para mamíferos. Todavia, estudos adicionais avaliando outras espécies do gênero, incluindo P. aphanidermatum precisam ser realizados.

Contribuição de cada autor no trabalho: todos os autores foram imprescindíveis para o desenvolvimento das diferentes etapas.

Zambrano C.G.: execução de todas as etapas do trabalho, que incluíram: coleta das águas, isolamento, caracterização morfológica, experimento in vivo, análise dos resultados e elaboração do manuscrito. Este trabalho é parte integrante da tese deste autor.

Fonseca A.O.S.: caracterização morfológica, desenvolvimento do experimento in vivo, análise dos resultados e elaboração do manuscrito.

Valente J.S.S.: execução de todas as etapas do trabalho, que incluíram: coleta das águas, isolamento, caracterização morfológica, experimento in vivo e elaboração do manuscrito.
Braga C.Q.: auxilio nas seguintes etapas do trabalho: preparo dos meios de cultura e material de coleta, coleta das águas, isolamento, caracterização morfológica e execução do experimento in vivo.

Sallis E.S.V.: responsável pela avaliação histopatológica das lesões nos animais, análise dos resultados e elaboração do manuscrito.

Azevedo M.I.: execução da identificação e caracterização molecular dos isolados, bem como auxilio na análise dos resultados e elaboração do manuscrito.

Weiblen C.: execução da identificação e caracterização molecular, análise dos resultados e auxílio na elaboração do manuscrito.

Santurio J.M.: auxilio na elaboração do trabalho e no suporte financeiro do projeto, bem como auxílio na análise dos resultados e elaboração do manuscrito.

Botton S.A.: auxilio na elaboração do trabalho, participação em todas as etapas desenvolvidas, incluindo: coleta de águas, identificação morfológica e molecular, análise dos resultados e elaboração do manuscrito. Também responsável pelo suporte financeiro do trabalho.

Pereira D.I.B.: responsável pela elaboração e execução do trabalho, incluindo as atividades desenvolvidas em todas as etapas (coleta das águas, isolamento, caracterização morfológica e molecular, experimento in vivo, análise dos resultados e elaboração do manuscrito). Responsável pelo suporte financeiro do trabalho e coordenadora do projeto, bem como orientadora do primeiro autor.

\section{REFERÊNCIAS}

Alexopoulos C.J., Mims C.W. \& Blackwell M. 1996. Phylum Oomycota, p.683-737. In: Ibid. (Eds), Introductory Mycology. 4th ed. Wiley, New York.

Adhikari B.N., Hamilton J.P., Zerillo M.M., Tisserat N., Lévesque C.A. \& Buell C.R. 2013. Comparative genomics reveals insight into virulence strategies of plant pathogenic oomycetes. PLOS One 8(10):75072.

Ali-Shtayeh M.S., Chee-Len L. \& Dick M.W. 1986. An improved method and medium for quantitative estimates of populations of Pythium species from soil. Trans Brit. Mycol. Soc. 86(1):39-47.

Azevedo M.I., Pereira D.I.B., Botton S.A., Costa M.M., Mahl C.D., Alves S.H. \& Santurio J.M. 2012. Phylogenetic relationships of Brazilian isolates of Pythium insidiosum based on ITS rDNA and cytochrome oxidase II gene sequences. Vet. Microbiol. 159(1/2):141-148.

Calvano T.P., Blatz P.J., Vento T.J., Wickes B.L., Sutton D.A., Thompson E.H., White C.E., Renz E.M. \& Hospenthal D.R. 2011 Pythium aphanidermatum Infection following Combat Trauma. J. Clin. Microbiol. 49(10):37103713.

Chaffin M.K., Schumacher J. \& Mcmullan W.C. 1995. Cutaneous pythiosis in the horse. Vet. Clin. North Am., Equine Pract. 11(1):91-103.

De Cock A.W., Mendoza L., Padhye A.A., Ajello L. \& Kaufman L. 1987. Pythium insidiosum sp. nov. the etiologic agent of pythiosis. J. Clin. Microbiol. 25(2):344-349.

Farmer A.R., Murray C.K., Driscoll I.R., Wickes B.L., Wiederhold N., Sutton D.A., Sanders C., Mende K., Enniss B., Feiq F., Ganesan A., Rini E.A. \& Vento T.J. 2015. Combat-related Pythium aphanidermatum invasive wound infection: case report and discussion of utility of molecular diagnostics. J. Clin. Microbiol. 53(6):1968-1975.

Fonseca A.O., Botton S.A., Nogueira C.E., Corrêa B.F., Silveira J.S., Maroneze B.P., Santurio J.M. \& Pereira D.I.B. 2014. In vitro reproduction of the life cyle of Pythium insidiosum from kunkers' equine and their role in the epidemiology of pythoisis. Mycopathologia 177(1/2):123-127.

Fonseca A.O., Pereira D.I.B., Botton S.A., Pötter L., Sallis E.S.V., Júnior S.F.V., Filho F.S.M., Zambrano C.G., Maroneze B.P., Valente J.S.S., Baptista C.T., Braga C.Q., Dal Ben V. \& Meireles M.C.M. 2015. Treatment of experimental pythiosis with essential oils of Origanum vulgare and Mentha piperita singly, in association and in combination with immunotherapy. Vet. Microbiol. 178(3/4):265-269.

Gaastra W., Lipman L.J.A., De Cock A.W.A.M., Exel T.K., Pegge R.B.G., Scheurwater J., Vilela R. \& Mendoza L. 2010. Pythium insidiosum: an overview. Vet. Microbiol. 146(1/2):1-16.

Jiang R.H.Y. \& Tyler B.M. 2012. Mechanisms and evolution of virulence in oomycetes. Annu. Rev. Phytopathol. 50:295-318. 
Kageyama K. 2014. Molecular taxonomy and its application to ecological studies of Pythium species. J. Gen. Plant Pathol. 80(4):314-326.

Klassen G.R., Balcerzak M. \& De Cock A.W.A.M. 1996. 5S ribosomal RNA gene spacer as species specific probes for eight species of Pythium. Phytopathology 86:581-587.

Krajaejun T., Sathapatayavongs B., Pracharktam R., Nitiyanant P., Leelachaikul P., Wanachiwanawin W., Chaiprasert A., Assanaden P., Saipetch M., Mootsikapun P., Chetchotisakd P., Lekhakula A., Mitarnun W., Kalnauwakul S., Supparatpinyo K., Chaiwarith R., Chiewchanvit S., Tananuvat N., Srisiri S., Suankratay C., Kulwichit W., Wongsaisuwan M. \& Somkaew S. 2006. Clinical and epidemiological analyses of human pythiosis in Thailand. Clin. Infect. Dis. 43:569-576.

Marcolongo-Pereira C., Sallis E.S.V., Raffi M.B., Pereira D.I.B., Hinnah F.L., Coelho A.C.B. \& Schild A.L. 2012. Epidemiologia da pitiose equina na região sul do Rio Grande do Sul. Pesq. Vet. Bras. 32(9):865-868.

Mendoza L. \& Prendas J. 1988. A method to obtain rapid zoosporogenesis of Pythium insidiosum. Mycopathologia 104:59-62.

Mendoza L., Hernandez F. \& Ajello L. 1993. Life cycle of the human and animal oomycete pathogen Pythium insidiosum. J. Clin. Microbiol. 31(11): 2967-2973.

Mendoza L., Ajello L. \& Mcginnis M.R. 1996. Infections caused by the oomycetous pathogen Pythium insidiosum. J. Mycol. Med. 6(4):151-164.

Mendoza L. \& Vilela R. 2013 The mammalian pathogenic oomycetes. Curr. Fungal Infect. Rep. 7(3):198-208.

Miller R.I. 1983. Investigations into the biology os three 'phycomycosis' agents pathogenic for horses in Australia. Mycopathologia 81:23-28.

Miller R.I. \& Campbell R.S.F. 1983. Experimental pythiosis in rabbits. Sabouraudia 21:331-341.

Möller E.M., Bahnweg G., Sandemann H. \& Geiger H.H. 1992. A simple and efficient protocol for isolation of high molecular weight DNA from filamentous fungi, fruit bodies, and infected plant tissues. Nucleic Acids 20:6115-6116.
Pereira D.I.B., Santurio J.M., Alves S.H., Argenta J.S., Potter L., Spanamberg A. \& Ferreiro J. 2007. Caspofungin in vitro and in vivo activity against Brazilian Pythium insidiosum strains isolated from animals. J. Antimicrob. Chemother. 60(5):1168-1171.

Pereira D.I.B., Santurio J.M., Alves S.H., Azevedo M.I., Silveira F., Costa F.F., Sallis E.S.V., Pötter L. \& Ferreiro L. 2008. Comparison between the immunotherapic Pitium Vac and the antifungal drug caspofungin as agents to treat experimental pythiosis in rabbits. J. Mycol. Med. 18:129-133.

Pittis J.E. \& Colquhoun J. 1984. Isolation and identification of pythiaceous fungi from irrigation water and their pathogenicity to Antirrhinum, tomato and Chamaecyparis lawsoniana. J. Phytopathol. 110:301-318.

Plaats-Niterink A.J. 1975. Species of Pythium in the Netherlands. Netherlands J. Plant Pathol. 81:22-37.

Presser J.W. \& Goss E. 2015. Environmental sampling reveals that Pythium insidiosum is ubiquitous and genetically diverse in North Central Florida. Med. Mycol. 53(7):674-83.

Santos C.E.P., Ubiali D.G., Pescador C.A., Zanette R.A., Santurio J.M. \& Marques L.C. 2014. Epidemiological survey of equine pythiosis in the Brazilian Pantanal and nearby areas: Results of 76 cases. J. Equine Vet. Sci. 34:270-274.

Santurio J.M., Leal A.T., Leal A.B.M., Festugatto R., Lubeck I., Sallis E.S.V., Copetti M.V., Alves S.H. \& Ferreiro F. 2003. Three types of immunotherapics against pythiosis insidiosi developed and evaluated. Vaccine 21:25352540 .

Supabandhu J., Fisher M.C., Mendoza L. \& Vanittankom N. 2008. Isolation and identification of the human pathogen Pythium insidiosum from environmental samples collected in Thai agricultural areas. Med. Mycol. 46(1):41-52.

Weiblen C., Machado G., Jesus F.P.K., Santurio J.M., Zanette R.A., Pereira D.I.B., Diehl G.N., Santos L.C., Corbellini L.G. \& Botton S.A. 2015. Seroprevalence of Pythium insidiosum infection in equine in Rio Grande do Sul, Brazil. Ciencia Rural 46(1):126-131. 